\title{
APROXIMACIÓN A LA TEORÍA LITERARIA DE LUIS CERNUDA: EL SURREALISMO
}

\author{
Francisco J. García Morilla
}

\section{I.- LUIS CERNUDA Y EL SURREALISMO}

En el "Primer Manifiesto" del surrealismo, publicado en 1924 por André Breton ${ }^{1}$, aparecen ciertas afirmaciones con las que Cernuda podía sentirse identificado. Así, es fácil imaginar el entusiasmo de Cernuda ante declaraciones como la que abre el "Manifiesto": "Tanta fe se tiene en la vida, en la vida en su aspecto más precario, en la vida real, naturalmente, que al fin esta fe acaba por desaparecer [...]. Si le queda [al hombre] un poco de lucidez, no tiene más remedio que dirigir la vista hacia atrás, hacia su infancia que siempre le parecerá maravillosa [...]. En la infancia, la ausencia de toda norma conocida ofrece al hombre la perspectiva de múltiples vidas vividas al mismo tiempo; el hombre hace suya esta ilusión; sólo le interesa la facilidad momentánea, extremada, que todas las cosas ofrecen"2. Y, más adelante, se afirma que "el espíritu que se sumerge en el surrealismo revive exaltadamente la mejor parte de su infancia [...]. Quizá sea vuestra infancia lo que más cerca se encuentra de la "verdadera vida" [...], esa infancia en la que todo favorece la eficaz, y sin azares, posesión de uno mismo. Gracias al surrealismo, parece que las oportunidades de la infancia reviven en nosotros. Es como si uno volviera a correr en pos de su salvación, o de su perdición"3.

Aparece aquí, y como uno de los fundamentos del surrealismo, el mito de la infancia como paraíso perdido, que es también uno de los elementos esenciales de la poética de Cernuda $^{4}$. La infancia es un mundo de felicidad pura y serena, de máxima libertad. El sentimiento de haber perdido ese mítico edén natural que Cernuda poseyó en la niñez, aparece por primera vez en sus libros surrealistas. Aquí trata de recuperarlo, de establecer un

\footnotetext{
1 A. Breton: "Primer Manifiesto del Surrealismo (1924)", en A. González García, F. Calvo Serraller, S. Marchán Fiz: Escritos de arte de vanguardia 1900/1945, Madrid, Turner/Fundación F. Orbegozo, 1979, págs. 347-361.

2 Op. cit., pág. 346.

3 Ibid., págs. 360-361.

4 Basta recordar los poemas en prosa de Ocnos (cuya primera redacción data de los años 1938-1947), magnífica recreación lírica de su infancia en Sevilla, símbolo perfecto e ideal de la vida, donde reina la belleza y la libertad en el esplendor de una naturaleza edénica y donde queda abolido el paso del tiempo. Es un mundo mítico, lejano, perfecto y eterno.
} 
puente de unión con ese mundo natural, a través del amor -otro tema fundamental en la poesía de Cernuda y también del surrealismo ${ }^{5}$-. El amor, tanto para Cernuda como para los surrealistas, era un sentimiento subversivo, socialmente inmoral; la pasión del amor, en general y no sólo del homosexual, rompe con la normas morales y las leyes establecidas de la sociedad.

El amor lleva al deseo, la auténtica verdad, en un intento imposible de recuperar la armonía de la infancia ${ }^{6}$. Por tanto, el deseo se transforma en una realidad en sí, perfecta. El deseo es más real que la realidad, que se vuelve irreal. Este es el centro de toda la poesía de Cernuda: el conflicto entre la realidad y el deseo (y es el título que ya en 1936 da a toda su obra poética $)^{7}$. La dualidad cernudiana guarda cierta relación con las teorías psíquicas de Freud, basadas en el placer y en el conflicto entre el sueño y la realidad, que tanto influyeron en los surrealistas ${ }^{8}$.

Así, en el "Primer Manifiesto" declara Breton: "Creo en la futura armonización de estos dos estados, aparentemente tan contradictorios, que son el sueño y la realidad, en una especie de realidad absoluta, en una sobrerrealidad o surrealidad [...]. Esta es la conquista que pretendo, en la certeza de jamás conseguirla"9. Quizá Cernuda vio también una posible reconciliación de su conflicto entre realidad y deseo mediante el surrealismo ${ }^{10} \mathrm{y}$, al igual que Breton, también era consciente de la inutilidad de su intento. Esta postura nihilista es típica del surrealismo, heredero del movimiento dadá; pero, frente a éste, el surrealismo supone una superación del negativismo, ya que proclama una afirmación absoluta más allá de todos los límites del deseo frente a la realidad. Afirmación del amor, única forma de conocimiento, única forma de existencia. Y se vuelve al amor, punto donde convergen la realidad y el deseo. Como afirma O. Paz: "El amor le revela la realidad al deseo [...]. Por el amor el deseo toca al fin la realidad: el otro existe. Esta revelación casi siempre es dolorosa porque la existencia del otro se nos presenta simultáneamente como un cuerpo que se penetra y como

\footnotetext{
${ }^{5}$ El propio Cernuda, en un artículo dedicado a Vicente Aleixandre, afirmaba que "para los surrealistas era el amor sentimiento avasallador y exclusivo, como lo demuestra la encuesta que sobre el amor realizó La Revolución Surrealista entre los adherentes al grupo, cuyas respuestas publicó en uno de sus números". I. Cernuda: Crítica, ensayos y evocaciones, Barcelona, Seix Barral, 1970, pág. 230.

6 Sin embargo, ante la certeza de que la correspondencia entre realidad y deseo es efímera, surge su rebeldía. Como dice L. Maristany: "El deseo constituye la gran fuerza activa, el motor unificador de las potencias humanas, tanto en el orden psíquico como en el social. Es, por tanto, un concepto subversivo que se orienta hacia la acción: la voluntad de destruir aquellos lazos -bien sean impuestos por la familia, el Estado o la religión- que en todo momento lo constriñen", L. Maristany: "La poesía de Luis Cernuda", en D. Harris (ed.): Luis Cernuda, Madrid, Taurus, 1984, pág. 191.

7 Vid. el reciente estudio de M.V. Utrera Torremocha: Luis Cerenuda: una poética entre la realidad y el deseo, Sevilla, Diputación Provincial de Sevilla, 1995.

8 Como afirma A. Breton: "Debemos reconocer que los descubrimientos de Freud han sido de decisiva importancia. Con base a dichos descubrimientos, comienza al fin a perfilarse una corriente de opinión [...] al quedar autorizado a dejar de limitarse, únicamente a las realidades más someras", A. González García et al.: Op. cit., p. 348.

${ }^{9}$ Ibid., pág. 351.

10 "El intento de resolver esta antinomia de la realidad y el deseo está en la misma raíz de la empresa surrealista", C. Marcial de Onís: El surrealismo y cuatro poetas de la generación del 27, Madrid, José Purrúa Turanzas, 1974, pág. 211.
} 
una conciencia impenetrable [...]. Y en esto radica la contradicción del amor; el deseo aspira a consumarse mediante la destrucción del objeto deseado; el amor descubre que ese objeto es indestructible... e insustituible. Queda el deseo sin amor o el amor sin deseo. El primero nos condena a la soledad: esos cuerpos intercambiables son irreales; el segundo es inhumano; ¿puede amarse aquello que no se desea?"11.

Consecuentemente, Cernuda se ve abocado a la soledad, al aislamiento ${ }^{12}$, otro tema fundamental para el surrealismo; así, en el "Primer Manifiesto" se afirma que "el Surrealismo únicamente podrá explicar el estado de completo aislamiento al que esperamos llegar, aquí, en esta vida"13.

Como se ha podido ver, son muchas, y sobre todo esenciales, las coincidencias entre la poética de Cernuda y las características teóricas del surrealismo. No obstante, también se puede encontrar influencias en las técnicas de expresión y en los aspectos formales. Estos aspectos serán analizados más adelante, cuando se estudien con detenimiento sus libros surrealistas.

Sin embargo, a pesar de estas similitudes y aproximaciones, la adhesión de Cernuda al surrealismo se produjo por el profundo sentido espiritual que latía en el centro del movimiento ${ }^{14}$.

Es muy reveladora, en este sentido, la "Declaración del 27 de enero de 1925", hecha por la Oficina de Investigaciones Surrealistas, donde se dice que "el Surrealismo no es un medio de expresión nuevo o más fácil, ni siquiera una metafísica de la poesía; Es un medio de liberación total del espíritu [...] Nos dirigimos de manera especial al mundo occidental: el surrealismo existe [...]. El surrealismo no es una forma poética. Es un grito del espíritu que se revuelve sobre sí mismo y que está totalmente dispuesto a triturar sus entrañas". También, A. Artaud, en "La actividad de la Oficina de Investigaciones Surrealistas (1925)", afirma: "El hecho de una revolución surrealista en las cosas es aplicable a todos los estados de espíritu, a todos los géneros de la actividad humana, a todos los estados del mundo de carácter espiritual, a todas las posiciones morales, a todos los órdenes del espíritu"15.

Cernuda, gran conocedor del movimiento surrealista francés ${ }^{16}$, seguramente había leído estos textos, especialmente durante su estancia en Francia ${ }^{17}$. De esta manera no es de

11 O. Paz: "La palabra edificante", en D. Harris (ed.): Op. cit., pág. 153. Este artículo es uno de los más inspirados y clarividentes estudios de la crítica cernudiana.

12 Este tema es recurrente, como se puede ver en los poemas "Quisiera estar solo en el sur", "Destierro" o "Dejadme solo" de Un río, un amor y "Esperaba solo" o "Déjame esta voz" de Los placeres prohibidos, L. Cernuda: La Realidad y el Deseo (1924-1962), Madrid, Taurus, 1991, págs. 47, 50, 63, 78 y 80 , respectivamente.

13 A. González García et al: : Op. cit., pág. 369

${ }^{14}$ La siguiente declaración de Cernuda revela claramente su opinión al respecto: "El superrealismo no fue sólo, según creo, una moda literaria, sino además algo muy distinto: una corriente espiritual en la juventud de una época, ante la cual yo no pude, ni quise, permanecer indiferente", L. Cernuda: La Realidad... cit., pág. 391.

15 A. González García et al.: Op. cit., págs. 362 y 363, respectivamente.

16 Vid. C. B. Morris: "Un poema de Luis Cernuda y la literatura surrealista", en V. García de la Concha (ed.): El Surrealismo, Madrid, Taurus, 1982, págs. 299-302. El propio Cernuda ha hecho referencias en sus escritos a 
extrañar la clara identificación entre sus declaraciones y los textos teóricos de los surrealistas franceses.

Por tanto, Luis Cernuda fue conscientemente un poeta surrealista. Es cierto que lo fue de forma pasajera ${ }^{18}$, pero las propias características de los movimientos literarios de vanguardia no permiten sino de una manera fugaz pertenecer a ellos. La fugacidad es el elemento que caracteriza a todos estos "ismos". Por consiguiente, la pertenencia o adhesión a algunos de ellos sólo podía darse durante un breve período de tiempo. Además, estos movimientos literarios se trivializaron en seguida, convirtiéndose en gastadas fórmulas literarias de las que el verdadero creador debía huir ${ }^{19}$.

La adhesión de Cernuda al surrealismo se produce durante los años 1929 y 1931. Por tanto, los poemas escritos bajo el influjo surrealista son los que pertenecen a los libros Un río, un amor y Los placeres prohibidos. Sin embargo, para Cernuda el surrealismo fue más que un movimiento o escuela, fue una corriente espiritual de su época y él, que se sentía un poeta de su tiempo, no podía quedar al margen. Además, Cernuda es el único poeta de la Generación del 27 en el que encontramos una afirmación, sin evasivas ni ocultaciones, de la etapa surrealista ${ }^{20}$.

No obstante, es necesario aclarar que si su adhesión estética al surrealismo fue pasajera, lo esencial del movimiento, el sentimiento de libertad y rebeldía, de revolución espiritual, fue constante en la vida y en la obra de Cernuda ${ }^{21}$.

las lecturas de esa época: "El superrealismo, con sus propósitos y técnica, había ganado mi simpatía. Leyendo aquellos libros primeros de Aragon, de Breton, de Eluard, de Crevel, percibía como eran míos también el malestar y osadía que en dichos libros hallaban mi voz", L. Cernuda: La Realidad... cit., pág. 388. Y en una carta enviada a Higinio Capote en diciembre de 1929, le pide que le envíe a Madrid algunos libros que dejó en Sevilla: "Los libros que quisiera son Les pas perdus, de André Breton, Las Aventures de Telémaque, Le Libertinage y Le Paysan de Paris, de Louis Aragon", J. M. Capote Benot: El surrealismo en la poesía de Luis Cernuda, Sevilla, Publicaciones de la Universidad, 1976, pág. 272.

17 Cernuda fue nombrado, por intercesión de Pedro Salinas, lector de español en la Universidad de Toulouse (noviembre, 1928-junio, 1929). Durante su estancia en Francia, también visitó la capital, y es muy significativo al respecto, que uno de sus mejores recuerdos de París fuera éste: "Al pasar por el boulevard Saint-Michel, las librerías, con mesas desbordando libros en mitad de la acera, me detenían largo rato. Pasé allá el tiempo dedicado a ver, a pasear, a leer. Qué deseo sentía de quedarme indefinidamente", L. Cernuda: La Realidad... cit., pág. 391.

18 "Mi simpatía con el superrealismo sólo afecta a los poemas escritos entre 1929 y 1931", V. Bodini: Los poetas surrealistas españoles, Barcelona, Tusquets, 1971, pág. 116. No obstante, todavía perduró la estética surrealista algún tiempo más: "La lectura de Bécquer o, mejor, la relectura del mismo [...] me orientó hacia una nueva visión y expresión poéticas, aunque todavía apareciesen en ellas, aquí o allá, algunos relámpagos o vislumbres de la manera superrealista", L. Cernuda: La Realidad... cit., pág. 396.

19 Recordemos las siguientes palabras de Cernuda al respecto: "[El superrealismo] había deparado ya su beneficio, sacando a la luz lo que yacía en mi subconciencia, lo que hasta su advenimiento permaneció dentro de mí en ceguedad y silencio", ibid., pág. 396.

20 Vid. L. Cernuda: Estudios sobre poesía española contemporánea, Madrid, Guadarrama, 1975, págs. 145-152. En este ensayo declara Cernuda: "Pasada la etapa gongorina, tercera en su crisis de desarrollo, entra dicha generación [del 27], o al menos parte de ella, en su cuarta y última etapa; etapa determinada por una influencia nueva, también de origen francés: la superrealista", ibid., pág. 145.

21 "El poeta es siempre un rebelde", ibid., pág. 154. Vid. M.V. Utrera Toerremocha, op. cit., págs. 159-192. 
En realidad, la raíz del problema, a la hora de hablar del surrealismo en Cernuda, y por extensión del surrealismo español, es terminológica. Así, debemos distinguir entre el surrealismo como escuela o movimiento literario -con unas coordenadas cronológicas y espaciales- y el surrealismo como época o actitud -como revolución internacional de la juventud, como movimiento de rebeldía general, como corriente espiritual de Occidente-. Tanto el originario movimiento surrealista francés, como el movimiento surrealista español están dentro de la época o actitud surrealista, que en cada país se manifiesta con peculiaridades propias. La estética surrealista desaparece pronto; sin embargo, la actitud surrealista tendrá una gran vitalidad, aun mucho después de abandonada definitivamente su escritura.

Por lo tanto, visto de esta manera, se puede hablar de un surrealismo español, con diferencias respecto al francés, con carácter propio, y de autores surrealistas españoles con sus peculiares características. Es cierto que el surrealismo español no fue un movimiento organizado como el francés, es decir, no hubo manifiestos, ni actos públicos de grupo $^{22}$. Además, los poetas españoles influidos por el surrealismo (Aleixandre, Lorca, Alberti, Prados, Cernuda) usaron las técnicas y formas expresivas surrealistas, pero nunca siguieron el dogma bretoniano de la escritura automática sin control de la conciencia credora. Ahora bien, ¿qué escritor surrealista llevó a cabo verdaderamente la escritura automática?23

Entre los surrealistas españoles, también faltaron la doctrina y el dogma, para formar un movimiento compacto y organizado. Los surrealista españoles fueron individualistas y heterodoxos; no aceptaron los peculiares métodos del surrealismo francés, ni sus rígidas normas. Y fue precisamente esta heterodoxia lo que permitió a los surrealistas españoles realizar auténticas creaciones artísticas, apoyados en un mayor grado de libertad. No le falta razón a Luis Cernuda cuando afirma que "el superrealismo francés obtiene con Aleixandre en España lo que no obtuvo en su tierra de origen: un gran poeta" 24 , puesto que sus libros Espadas como labios y La destrucción o el amor cuentan entre las pocas obras de calidad (como Poeta en Nueva York de Federico García Lorca), que produjo el surrealismo en cualquier país. Por tanto, se da la paradoja de que los frutos del surrealismo español están entre lo mejor del movimiento surrealista precisamente por no ser muy surrealistas, o mejor dicho, por distanciarse de lo negativo que para la creación artística podían tener ciertos dogmas y preceptos surrealistas.

\footnotetext{
22 No obstante, Cernuda aporta la siguiente información al respecto: "Hace unos días hemos tramado una revista surrealista con títulos de este tono: Poesía y Destrucción, El Agua en la Boca, El Libertinaje", J. M. Capote Benot: Op. cit., pág. 275.

${ }^{23}$ Incluso A. Breton, en el "Segundo Manifiesto del Surrealismo" (1930), hace ciertas matizaciones sobre la idea de la escritura automática, vid. A. González García et al.: Op. cit., págs. 365-383; y ya en 1932 afirma: "Nunca hemos pretendido dar un texto surrealista cualquiera como ejemplo perfecto de automatismo verbal. Incluso en el mejor texto "no controlado" se advierten, hemos de reconocerlo, ciertas resistencias. En general, un mínimo de control subsiste, en el sentido del equilibrio poético", "Lettre à Roland de Rèneville", Nouvelle Revue Françcaise, $1^{\circ}$ de mayo de 1932, tomado de V. Bodini: "Características y técnicas del surrealismo español", en V. García de la Concha (ed.): Op. cit., pág. 106.

${ }^{24}$ L. Cernuda: Estudios... cit., pág. 151.
} 
Si se leen las páginas críticas de Cernuda, puede comprobarse que siempre hace una valoración positiva del surrealismo ${ }^{25}$, considerándolo como corriente espiritual de su época. Sin embargo, hoy no podemos seguir manteniendo este entusiasmo. Desde la perspectiva actual, la época vanguardista no es sino una entelequia. Y, aunque el surrealismo fue el movimiento más importante de las vanguardias y la más consciente de todas aquellas manifestaciones artísticas colectivas e, incluso, su influencia y beneficios han sido -y sonimportantes, no se debe olvidar que también ha supuesto el manto protector en el que se ha venido amparando (especialmente en las artes plásticas) una turbamulta de supuestos genios.

Además, el surrealismo tuvo más de declaración de intenciones que de verdaderos frutos. Y no se puede juzgar un movimiento por un puñado de buenos propósitos, sino por sus resultados; $y$, verdaderamente, son pocas las creaciones de auténtico valor que el surrealismo ha legado a la posteridad.

No obstante, entre sus méritos hay que contar la agitación artística, social e, incluso, moral que provocó en su época. Lo que ocurrió es que pronto se convirtió en una caricatura de sí mismo, pasando a ser un espectáculo y, sobre todo en las bellas artes, un lucrativo negocio.

\section{II.- EL SURREALISMO EN LA POESÍA DE LUIS CERNUDA}

Dentro de la etapa surrealista de Luis Cernuda se puede observar una clara evolución, marcada por dos momentos fundamentales, que coinciden con la publicación de sus libros Un río, un amor (1929) y Los placeres prohibidos (1931). En el primero, el surrealismo influye especialmente en lo formal y en la técnica. En el segundo, la influencia surrealista es más temática; el poeta expresa en sus poemas una nueva filosofía que afecta a su visión del mundo.

Esta evolución es muy normal. En un primer momento, y deslumbrado ante las posibilidades que el movimiento le ofrece, Cernuda empieza a escribir a la manera surrealista, pero aún no ha tenido tiempo de asimilar en profundidad las enseñanzas del movimiento. Por ello, la mayor influencia se produce en lo formal y externo, que es lo primero y lo que más fácilmente se adquiere de cualquier estilo o escuela literaria. Sin embargo, en lo que se refiere al contenido temático, todavía tiene una estrecha relación con sus libros anteriores. Así, el tema principal de Un río, un amor es la soledad del poeta que, sintiéndose marginado, acepta con orgullo, aunque pasivamente, su marginación. Esta actitud se puede ver en poemas como "Destierro" o "No intentemos el amor nunca"26.

\footnotetext{
25 "Sería un error grave estimarle como otro movimiento literario más entre los que anteriormente habían aparecido, porque de todos ellos el superrealismo fue el único que tuvo razón histórica de existir y contenido intelectual", ibid., pág. 145.

${ }^{26}$ L. Cernuda: La Realidad... cit., págs. 50 y 58, respectivamente.
} 
Más adelante, las características del surrealismo afectan más intensamente a la temática, al contenido de los poemas. Se reducen también las novedades formales a favor de la radicalidad en otros aspectos (morales, sociales, políticos, religiosos...). Esto demuestra que Cernuda ha asimilado más profundamente las influencias del surrealismo. Así, ahora adopta una actitud de clara rebeldía ante lo establecido, rechazando las leyes, las normas y los convencionalismos sociales. Ejemplo de esta nueva postura es el poema "Diré como nacisteis"27, que le permite a Cernuda expresar la naturaleza homosexual de sus inclinaciones amorosas ${ }^{28}$.

Especialmente interesante es el estudio de la métrica de los poemas surrealistas de Cernuda, sobre todo en cuanto al uso del verso libre y largo, y a la eliminación de la rima. Muchos poemas de esta época están escritos en una especie de verso libre, que realmente no es tal. En la poesía contemporánea se ha abusado del versolibrismo llegando, en muchos casos, a confundirlo con la prosa. Ésta es otra de las envenenadas herencias de las vanguardias a la poesía contemporánea. Puesto que, en realidad, el verso totalmente libre no existe $^{29}$. Y prueba de ello es el caso de Cernuda. Su personal modalidad de verso libre posee un sistema rítmico tradicional, donde se pone de manifiesto la línea melódica de sus poemas, que cualquier lector habitual de poesía debería percibir ${ }^{30}$. Generalmente, el ritmo es endecasilábico, donde se refleja un gusto por lo impar: versos de cinco, siete, nueve u once sílabas. Además, los versos largos, con apariencia de versículos, usados por Cernuda y que más cerca podrían estar del versolibrismo, en muchos casos no son otra cosa que combinaciones, en yuxtaposición, de versos tradicionales de menor número de sílabas. Por ejemplo, este verso de "Como la piel", uno de sus poemas más surrealistas ${ }^{31}$ : "Cuando una

27 Ibid., págs. 71-2.

28 En este sentido, también destacan otros poemas como "Adónde fueron despeñadas", "Los marineros son las alas del amor", "Quisiera saber porqué esta muerte" o "Que más da", ibid., págs. 73, 78, 79 y 84, respectivamente.

29 Puesto que en la mayoría de los llamados versos libres se pueden encontrar algunas pautas métricas, desde una cierta tendencia a reproducir determinados ritmos (endecasilábicos o hexamétricos), a una clara expresión de los esquemas rítmicos tradicionales. Vid. E. Torre y M. A. Vázquez, "El verso libre", en Fundamentos de Poética Española, Sevilla, Alfar, 1986, págs. 78-82.

30 Cernuda era consciente de ello, como lo demuestra la siguiente declaración: "Lo curioso es que, a pesar de ambas cosas, verso libre y ausencia de rima, en ocasiones sea visible en alguna de tales composiciones (por ejemplo "Estoy cansado") una intención análoga a la de la canción; creo que siempre ha sido constante en mis versos, aunque a intervalos, la aparición del poema-canción. Pero no quería repetir la forma y la manera de las canciones medievales, ni de las letrillas, sino, con impulso semejante, conseguir otra expresión. Inútil añadir que nadie se dio cuenta de mi propósito", L. Cernuda: La Realidad... cit., pág. 392.

31 Pertenece a Un río, un amor (L. Cernuda: La Realidad... cit., págs. 67-68), y es uno de los textos de Cernuda que más cerca están de la escritura automática, como se puede apreciar en la siguiente estrofa:

En un mundo de alambre

Donde el olvido vuela por debajo del suelo,

En un mundo de angustia,

Alcohol amarillento,

Plumas de fiebre,

Ira subiendo a un cielo de vergüenza,

Algún día nuevamente resurgirá la flecha 
estrella muere como otoño para olvidar su sombra". Aquí se puede observar como un verso largo de dieciocho sílabas, en realidad es una composición formada por un endecasílabo seguido de un heptasílabo:

Cuando una estrella muere como otoño para olvidar su sombra.

La verdadera concesión a la libertad expresiva es que prescinde de la rima ${ }^{32}$. Sin embargo, el resto del aparato métrico de sus libros surrealistas está en la estela de la retórica tradicional. No hay que olvidar su formación clásica en el ritmo poético. Además, Cernuda acababa de escribir un libro de formas tan clásicas como Égloga, Elegía y Oda (1927-1928) y no logra prescindir del sistema rítmico en el que su oído se había educado. Por ello, no debe extrañar que su primer libro surrealista, Un río, un amor, comience con una serie de poemas escritos en cuartetos alejandrinos. Y que a lo largo de su etapa surrealista sean muy frecuentes las combinaciones de versos tradicionales de distintas medidas: alejandrinos, endecasílabos, eneasílabos, heptasílabos. Estos moldes clásicos se convertirán en un obstáculo a la hora de practicar el verso largo y libre; el propio Cernuda nos confiesa sus contrariedades: "Antes había tenido cierta dificultad en usar del verso libre; con el impulso que entonces me animaba, la dificultad quedó vencida, llegando a veces, tanto en Un río, un amor como en la colección siguiente, Los placeres prohibidos, a utilizar versos de extensión considerable, en realidad versículos"33.

Se puede apreciar cómo en Cernuda hay un intento de acercarse a la emancipación métrica propia del surrealismo, y en general, de todos los movimientos de vanguardia. Practicando el verso largo, Cernuda atentaba contra la medida y la forma tradicionales, y aunque al principio tuvo ciertas dificultades, y como ya se ha visto, más tarde las superó.

Por tanto, en el aspecto métrico -que parecía alejar a Cernuda de las directrices del movimiento surrealista y que ha sido uno de los principales argumentos para negar el surrealismo de su poesía- al menos destaca el intento, para Cernuda logrado, de usar el verso largo y libre, típico del surrealismo, a pesar de su educación en la tradición métrica.

En este sentido, otro aspecto que merece ser comentado es el abandono del uso de la puntuación ortográfica, no sólo en Un río, un amor y Los placeres prohibidos, sino también en los dos libros posteriores, siguiendo los "Secretos del arte mágico del surrealismo" de A. Breton, para lograr "la continuidad absoluta del fluir"34 del subconsciente, que la escritura automática propiciaba. Sin embargo, el propio Cernuda, cuando publica la primera edición de La realidad y el deseo (1936), puntúa estos cuatro libros, que inicialmente carecieron de puntuación.

Que abandona el azar

Cuando una estrella muere como otoño para olvidar su sombra.

32 Como reconoce el propio Cernuda, al comentar sus libros Un río, un amor y Los placeres prohibidos:

"Prescindí de la rima, consonante o asonante y apenas si, desde entonces, he vuelto a usar la primera", L. Cernuda: "Historial... cit., pág. 392.

33 Ibid., pág. 392.

34 A. González García et al.: Op. cit., pág. 365. 
Este rectificación puede suponer un alejamiento del surrealismo y parece contradecir la tesis propuesta en este estudio. Pero, como ya se ha dicho anteriormente, lo que hace Cernuda no es renegar del surrealismo, sino eliminar lo que tenía de superficial, de pose, de moda, quedándose con lo importante, con el espíritu del movimiento. La auténtica poesía es ajena a la moda. La poesía es tiempo, la moda es temporal; por tanto, la poesía es eterna y la moda poética es efímera. El surrealismo fue mucho más que una escuela literaria y, por tanto, los elementos formales (y la métrica lo es) son los más superficiales y llamativos de una manera determinada de escritura. Todo ello, viene a confirmar la tesis de que Cernuda fue surrealista y que lo esencial del movimiento perduró en su obra posterior.

Por lo dicho, pudiera parecer que Cernuda fue un surrealista de espíritu, y que en lo referente a la creación, quedó al margen de la técnicas surrealistas. Sin embargo, a Cernuda le atrajo del surrealismo tanto la ética como la técnica ${ }^{35}$.

En un breve, pero excelente, artículo de C. B. Morris, titulado "Un poema de Luis Cernuda y la literatura surrealista", se afirma: "Sin embargo, lo que no ofrece ningún misterio son los conocimientos que tenía Luis Cernuda de la literatura surrealista, de los que hizo alarde" 36 .

Rastreando las influencias de la literatura surrealista francesa en la obra de Cernuda, se encuentran reveladoras coincidencias. Así, en Un río, un amor aparecen imágenes como "jinete sin cabeza" del poema "Canción del oeste", y en Los placeres prohibidos destacan unos "ojos vacíos" y una "mano de yeso cortada", de los poemas "Pasión por pasión" y "Había en el fondo del mar", expresiones habituales de los surrealistas. Incluso, el "insomnio maquinal" que padece el ahogado de "Cuerpo en pena", de Un río, un amor, evoca los versos de Paul Eluard "les mouvements machinaux de l'insomnie" en su poema "Armure de proie le parfum noir rayonne" de L'Amour la poésie (además son evidentes las reminiscencias de este título en el del libro de Cernuda).

La exaltación que Cernuda hace de la libertad del mar, en el viaje del ahogado, en este poema ("en plena mar al fin, sin rumbo, a toda vela"), recuerda los versos de Eluard: "En pleine mer dans des bras délicats/ Aux breaux jours les vagues à toutes voiles". En este sentido, hay que recordar que el interés de Cernuda por el poeta francés, fundador del surrealismo y uno de sus principales animadores, le impulsó a traducir algunos de sus poemas $^{37}$, y esto puede explicar algunas semejanzas, mejor que influencias, entre ambos. En efecto, y como afirma V. Bodini ${ }^{38}$, la fidelidad al suspiro, la lenta música, el blanco deslumbrante de las cosas, la frente en los cristales de la ventana, ciertos mórbidos abismos o las lentas curvas de la angustia, son razones, más que efectos, de su labor traductora.

\footnotetext{
35 Prueba de ello es la siguiente afirmación: "El superrealismo, con sus propósitos y técnica, había ganado mi simpatía", L. Cernuda: "Historial... cit.", pág. 388.

36 C. B. Morris: Ob. cit., pág. 299. Vid. n. 16.

37 Vid. P. Eluard: "El amor, la poesía", Litoral, nº 9, junio, 1929, págs. 28-30.

38 V. Bodini: Op. cit., pág. 91.
} 
Para comprobar la influencia del surrealismo en Cernuda, lo más adecuado es realizar un estudio detenido del poema "En medio de la multitud" de Los placeres prohibidos ${ }^{39}$, Analizando este poema, no sólo se confirma el perfecto conocimiento que Cernuda tenía de la literatura surrealista, sino también el uso que hace de expresiones y temas propios del surrealismo ${ }^{40}$.

El protagonista del poema de Cernuda es un personaje fantasmal que vaga sin rumbo por la ciudad ("Vacío, anduve sin rumbo por la ciudad [...]. Anduve más y más"). Esta figura es similar a las descritas por numerosos autores surrealistas franceses. Así ocurre, por ejemplo, con Julien, el protagonista de la novela En joue! de P. Soupault, que "ne savait vraiment où diriger ses pas. Il cherchait un but devant lui"41; con Pierre, en La Mort difficile: "Seul, il ne saurait où fuir... Il marchait... Il marchait..."42; o con el Anicet de Aragon, que ansiaba "ne plus avoir de but dans la vie"43.

Estos paseos por la ciudad son típicos de los surrealistas, y con ellos quieren expresar la soledad y la incomunicación en que se encuentra el ser humano, a pesar de hallarse en una calle llena de gente. Esto es lo mismo que refleja el poema cernudiano y es un tema recurrente en su poesía ${ }^{44}$.

Este sentimiento provoca confusión ("la niebla me envolvía" del poema de Cernuda recuerda "un brouillard les enveloppe" del libro de Crevel) y angustia: "No sentía mis pies. Quise cogerlos en mi mano, y no hallé mis manos; quise gritar, y no hallé mi voz"; estas mutilaciones son similares a las sufridas por un hombre y una mujer en Les Épaves du ciel, de Reverdy: "C'est un homme sans pieds qui voudraient courier. Una femme sans tête qui voudraient parler" 45 . Ante esta situación de amargura y desesperanza, concluye Cernuda: "estaba muerto y andaba entre los muertos".

En definitiva, y en palabras de C. B. Morris, "lo que demuestra "En medio de la multitud", es que al proyectarse en una muchedumbre, Cernuda reproduce a la vez esa soledad y esa imponente falta de dirección, que tan importantes temas fueron para la literatura surrealista" 46 .

No parece necesario seguir apuntando posibles fuentes o coincidencias temáticas y estilísticas; valgan las citadas para comprobar que Cernuda utiliza conceptos y técnicas en la misma dirección que los surrealistas, situándose dentro de un movimiento más amplio de insatisfacción compartida. Además, según A. Breton, el éxito o fracaso del surrealismo

\footnotetext{
${ }^{39}$ L. Cernuda: La Realidad... cit., pág. 74.

40 Tanto las anteriores consideraciones sobre la literatura surrealista francesa, como las que aparecen a continuación, están basadas en C. B. Morris: Op. cit.

41 P. Soupault, En joue!, Paris, 1925, pág. 278.

42 R. Crevel, La Mort difficile, Paris, 1926, pág. 78

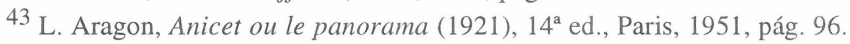

44 Vid. n. 10.

45 P. Reverdy, Les Épaves du ciel, $5^{\text {a }}$ ed., Paris, 1924, pág. 84.

46 C. B. Morris: Op. cit., pág. 302.
} 
únicamente se puede determinar valorando si logró o no "provocar, en lo intelectual y lo moral, una crisis de conciencia del tipo más general y más grave posible"47. Y, al margen de que históricamente lo consiguiera o no, es indudable que también ese era el objetivo de Cernuda $^{48}$.

La valoración que se suele hacer de la etapa surrealista en la poesía de Luis Cernuda es muy desigual. No obstante, es un lugar común en los estudios cernudianos considerarla una período fundamental en su evolución poética.

Sin olvidar la cimas a las que llegó Cernuda con su poesía de madurez, se puede concluir este estudio con las siguientes palabras de O. Paz: "El libro de poemas de Cernuda [se refiere a La Realidad y el Deseo] podría dividirse en cuatro partes [...] Momentos distintos de una misma palabra. En cada uno hay poemas admirables pero yo me quedo con la poesía de juventud (Los placeres prohibidos, Un río, un amor, Donde habite el olvido, Invocaciones) no porque en esos libros el poeta sea enteramente dueño de sí sino precisamente porque todavía no lo es: instante en que la adivinación aún no se vuelve certidumbre ni la certidumbre, fórmula" 49 .

47 A. González García et al.: Op. cit., pág. 365.

48 Como afirma O. Paz: "Para Cernuda el surrealismo fue algo más que una lección de estilo, más que una poética o una escuela de asociaciones e imágenes verbales: fue una tentativa de encarnación de la poesía en la vida, una subversión que abarcaba tanto al lenguaje como a las instituciones. Una moral y una pasión. Cernuda fue el primero, y casi el único, que comprendió e hizo suya la verdadera significación del surrealismo como movimiento de liberación -no del verso sino de la conciencia-: el último gran sacudimiento espiritual de Occidente", V. García de la Concha (ed.): Op. cit., pág. 143.

${ }^{49}$ Ibid., pág. 141. 


\section{BIBLIOGRAFÍA}

AA.VV.: A una verdad. Luis Cernuda (1902-1963), Sevilla, Universidad Internacional Menéndez Pelayo, 1988.

ALEIXANDRE, V.: Poesía surrealista. Antología, Barcelona, Barral Editores, 1971.

ALONSO, D.: Poetas españoles contemporáneos, Madrid, Gredos, 1952.

ARMIÑO, M.: Antología de la poesía surrealista, Madrid, Visor, 1971.

BARÓN PALMA, E.: Luis Cernuda: vida y obra, Sevilla, Editoriales Andaluzas Unidas, 1990.

BODINI, V: Los poetas surrealistas españoles, Barcelona, Tusquets, 1971.

BRETON, A.: "Primer Manifiesto del Surrealismo (1924)", en A. González García, F. Calvo Serraller, S. Marchán Fiz, Escritos de arte de vanguardia 1900/1945, Madrid, Turner/Fundación F. Orbegozo, 1979, págs. 347-361.

BRETON, A.: "Segundo Manifiesto del Surrealismo (1930)", en A. González García, F. Calvo Serraller, S. Marchán Fiz, Escritos de arte de vanguardia 1900/1945, Madrid, Turner/Fundación F. Orbegozo, 1979, págs. 365-383.

BUCKLEY, R.: "¿Surrealismo en España?, Ínsula, n 337, 1974, págs. 4-5.

CANO, J. L.: "Una antología del surrealismo español", Ínsula, n 337, 1974, págs. 10-11.

CAPOTE BENOT, J. M.: El surrealismo en la poesía de Luis Cernuda, Sevilla, Publicaciones de la Universidad de Sevilla, 1976.

CERNUDA, L.: Crítica, ensayos y evocaciones, Barcelona, Seix Barral, 1970.

CERNUDA, L.: Estudios sobre poesía española contemporánea, Madrid, Guadarrama, 1975. CERNUDA, L.: "Historial de un libro (La Realidad y el Deseo) (1858)", en La Realidad y el Deseo (1924-1962), Madrid, Taurus, 1991, págs. 379-420.

CERNUDA, L.: "Palabras antes de una lectura (1935)", en Poesía y Literatura, Barcelona, Seix-Barral, 1960, págs. 193-201.

CERNUDA, L.: Pensamiento poético en la lírica inglesa (siglo XIX), México, Imprenta Universitaria, 1958.

CERNUDA, L.: Poesía y Literatura, Barcelona, Seix-Barral, 1960.

CERNUDA, L.: La Realidad y el Deseo (1924-1962), Madrid, Taurus, 1991.

GAOS, V.: Antología del grupo poético de 1927, Madrid, Cátedra, 1982.

GARCÍA DE LA CONCHA, V. (ed.): El Surrealismo, Madrid, Taurus, 1982.

GIL DE BIEDMA, J., GIL ALBERT, J. Y VILLENA, L. A. DE: 3 Luis Cernuda, Sevilla, Secretariado de Publicaciones de la Universidad de Sevilla, 1977. 
GONZÁlEZ GARCÍA, A., CALVO SERRALLER, F., MARCHÁN FIZ, S.: Escritos de arte de vanguardia 1900/1945, Madrid, Turner/Fundación F. Orbegozo, 1979.

GOYTISOLO, J.: "Homenaje a Luis Cernuda", en D. Harris (ed.), Luis Cernuda, Madrid, Taurus, 1984, págs. 161-175.

GULlón, R.: "La poesía de Luis Cernuda", en D. Harris (ed.), Luis Cernuda, Madrid, Taurus, 1984, págs. 71-88.

HARRIS, D. (ed.), Luis Cernuda, Madrid, Taurus, 1984.

HARRIS, D. Y MARISTANY, L. (eds.): Poesía completa, Siruela, 1993.

HARRIS, D. Y MARISTANY, L. (eds.): Prosa completa, Barcelona, Barral, 1975.

ILIE, P.: Los surrealistas españoles, Madrid, Tusquets, 1982.

MARCIAL DE ONÍS, C.: El surrealismo y cuatro poetas de la generación del 27, Madrid, José Purrúa Turanzas, 1974.

MARISTANY, L.: "La poesía de Luis Cernuda", en D. Harris (ed.), Luis Cernuda, Madrid, Taurus, 1984, págs. 185-202.

MORRIS, C. B.: "Un poema de Luis Cernuda y la literatura surrealista", en V. García de la Concha (ed.), El Surrealismo, Madrid, Taurus, 1982, págs. 299-302.

MORRIS, C. B.: Una generación de poetas españoles (1920-1936), Madrid, Gredos, 1988.

PAZ, O.: "La palabra edificante", en D. Harris (ed.), Luis Cernuda, Madrid, Taurus, 1984, págs. 138-160.

REAL RAMOS, C.: Luis Cernuda y la "Generación del 27", Salamanca, Universidad de Salamanca, 1983.

SÁNCHEZ ROSILlo, E.: La fuerza del destino. Vida y poesía de Luis Cernuda, Murcia, Secretariado de Publicaciones de la Universidad de Murcia, 1992.

TORRE, E. y VÁZQUEZ, M.A.: Fundamentos de poética española, Sevilla, Alfar, 1986.

UTRERA TORREMOCHA, M.V.: Luis Cernuda: una poética entre la realidad y el deseo, Sevilla, Diputación Provincial de Sevilla, 1995.

VILLENA, L. A.: "Luis Cernuda y el fuego superrealista", Ínsula, n³37, 1974, pág. 4.

VILLENA, L. A.: "La rebeldía del dandy en Luis Cernuda", en J. Gil de Biedma, J. Gil Albert y L. A. de Villena, 3 Luis Cernuda, Sevilla, Secretariado de Publicaciones de la Universidad de Sevilla, 1977, págs. 109-55. 
